DOI 10.37882/2223-2982.2021.05.08

\title{
ИГРОВАЯ АФФИКСАЦИЯ СУЩЕСТВИТЕЛЬНЫХ В СОВРЕМЕННОМ РУССКОМ ЯЗЫКЕ
}

\section{GAME AFFIXATION OF NOUNS IN THE MODERN RUSSIAN LANGUAGE \\ P. Grigorieva}

Summary: This article is devoted to the topic of game affixation of nouns: the definition of the concept of game affixation is given, game nouns-prefixes, suffixes, as well as game nouns formed by the prefixsuffix method are analyzed. Prefixes involved in the formation of game nouns-prefixes are few in number. The suffixes involved in the formation of game nouns-suffixes are divided into groups depending on the game component. Game nouns formed in the prefix-suffix way are divided into three types according to the models of their formation.

Keywords: game nouns, game affixation, game word formation, game prefixing.
Григорьева Полина Вениаминовна

Аспирант, МГУ имени М.В. Ломоносова paulines@yandex.ru

Аннотация: Статья посвящена теме игровой аффиксации существительных: дано определение понятия игровой аффиксации, проанализированы игровые существительные-префиксаты, суффиксаты, а также игровые существительные, образованные префиксально-суффиксальным способом. Префиксы, участвующие в образовании игровых существительных-префиксатов, немногочисленны. Суффиксы, участвующие в образовании игровых существительных-суффиксатов, разделены на группы в зависимости от игровой составляющей. Игровые существительные, образованные префиксальносуффиксальным способом, разделены на три типа согласно моделям их образования.

Ключевые слова: : игровые существительные, игровая аффиксация, игровое словообразование, игровая префиксация.

\section{Игровая меривация как научное понятие}

И зучение игровых дериватов рубежа XX-XXI вв. - новое направление в исследованиях русской лексики. Распространение данного типа неузуальной лексики было обусловлено появлением в русскоязычном мире в конце XX века множества новых реалий, привнёсших в русский язык необходимость их номинации: «Язык, который существует в меняющемся мире и не меняется сам, перестаёт выполнять свою функцию» $[1$, с. 19]. Эти номинации, в свою очередь, обрели популярность благодаря появлению интернета.

В данной работе под результатом игрового словообразования мы будем понимать «словесную форму комического» [2, с. 16], так как целью языковой игры «является создание комического эффекта - языковой шутки» $[2$, c. 15$]$.

Определение В.3. Санникова [2], согласно которому игровое словообразование - это творческая интерпретация знаний систем единиц языка, дополняет определение игровой функции словообразования, данное Е.А. Земской. «Игровая функция выполняет и номинативную роль (игровое слово непременно именует что-либо), но в ней присутствует особое намерение говорящего - поиграть с формой речи, причем эта игра может быть и безобидной шуткой, и острой насмешкой, и злой иронией, и едким сарказмом» [3, с. 186]

Развитию игровой деривации способствовало «изме- нение отношения к понятию «норма»: норма перестала быть запретом, на место соотношения «норма - не норма» пришло соотношение «норма - другая норма». Другая норма - это коммуникативная, или ситуативная норма, то есть норма, уместная в данном контексте» $[4$, с. 4] Таким образом, при игровой деривации наличие игровой составляющей важнее следования словообразовательным нормам русского языка. В качестве игровых элементов могут выступать морфемы и морфемоподобные сочетания (в частности, имеющиеся в группах слов с общим элементом семантики: -фон (бадафон, яблофон, ср. телефон), -тека (алкотека, вкуснотека ср. библиотека), гор- (горивет, мосгорпичиа, ср. горгаз) и т.д.), а также целые слова, такие, как бургер в составе деривата яйчебургер (ср. гамбургер), пичиа в составе деривата чебупицча (ср. чебурек и пицча), холод и мор в составе деривата холодомор (ср. голодомор).

Итак, игровой дериват - это «такое преднамеренно созданное производное слово, которое вследствие своей яркой внутренней формы, призванной создать комический эффект, становится средством языковой игры и выполняет игровую функцию». [5, с. 52-53]

\section{Игровая аффиксачия как поАвиА игровой меривашии}

Игровая деривация как способ создания неузуальной лексики оперирует двумя группами способов словообразования: аффиксальными и неаффиксальными (блендинг, граффиксация, см. [6]). 
В аффиксальных способах словообразования «основным средством выражения деривационного значения является аффикс» [7, с. 308].

Система аффиксальных способов словообразования, используемых в узуальном словообразовании (префиксация, суффиксация, постфиксация, а также различные комбинированные аффиксальные способы), в игровом словообразовании претерпевает сужение. Как показывает анализ языкового материала, далеко не все узуальные аффиксальные способы образования слов годны для образования игровых дериватов. Сравнение узуальных способов аффиксации с неузуальными показывает, что алгоритмы аффиксации в случае игровой лексики применяются с нарушением закономерностей их использования.

\section{Игровые Аериваты-аффиксаты: отграничение от смежных способов словообразования}

Анализируя способ образования того или иного игрового деривата, необходимо корректно расшифровывать его внутреннюю форму с целью понимания того, аффикс или же часть слова-стимула сформировали комизм, в частности, из-за сочетания несочетаемого.

Так, например, ранее упомянутые морфемоподобные сочетания (-фон, (бадафон), -тека (алкотека), гор- (горивет) и т.д.) в узуальном словообразовании являются либо второй основой, либо вообще частью единого корня. Комизм данного типа игровых дериватов выявляется не при анализе семантики слова-стимула и морфемоподобного сочетания, а при сопоставлении игрового деривата с узуальной лексемой или группой узуальных лексем, содержащих данное морфемоподобное сочетание. Например, игровой дериват вкуснотека сопоставляется с группой узуальных лексем (карто-, библио-, фонотека) и содержит морфемоподобное сочетание вкусно. В данном случае комизм усиливает то, что вкусно - это наречие, в отличие от узуальных лексем, являющихся существительными.

Граница игровой суффиксации и блендинга в некоторых игровых дериватах размыта. Так, например, возникает вопрос о том, с помощью какого способа словообразования создан игровой дериват Пирогерия. «Так, в бленде Пирогерия (название магазина по продаже пирогов) можно выделить составляющие пирог, и, предположительно, суффикс $-u[j]-$, встречающийся в топонимах (ср. Нигерия, Фанагория). Впрочем, если выделять корень пирог-/пирож- и суффикс -и[j]-, остаётся вопрос о том, чем является разделяющий их элемент [ер']» [6: 490]. Учитывая всё сказанное выше, логичнее всего отнести данный игровой дериват не к аффиксатам, а к блендам [6], к группе игровых дериватов, представляющих собой мнимые топонимы.
Подход с точки зрения блендинга позволяет продуктивно проанализировать уже имеющиеся игровые дериваты и окказионализмы. Так, в книге Т.В. Поповой «Русская неология и неография» встречаем окказионализм болитва, который, по мнению автора книги, является суффиксатом: «при образовании существительного болитва - непродуктивная модель: «глагол + -mв $(a)=$ существительное со значением отвлеченного действия» и неканонический для русского литературного языка глагол-мотиватор (бить - битва, болиться - болитва)» [8, с. 26]. Здесь представляется более рациональным не продуцировать несуществущий глагол болиться, а объяснить образование этого окказионализма как бленда, образованного при помощи сложения слов-стимулов болеть и молитва.

\section{Префиксашия}

В игровом словообразовании префиксация практически не распространена, возможно, в силу того, что семантическое значение приставки разнообразно, и на его основе трудно создать словообразовательный комический эффект.

Случаем игрового словообразования, который можно рассматривать в рамках префиксации, является дериват АрхиМед. Название данной сети медицинских центров образовано по звуковому образцу имени собственного греческого математика и физика Архимеда. Но в игровом деривате АрхиМед графически выделен псевдоэтимологический корень -мед-, указывающий на медицинский профиль сети учреждений. Широчайшая известность имени греческого учёного Архимеда в математике и физике позволяет привлечь внимание к игровому названию сети медицинских учреждений. В данном случае, в отличие от слов медбрат, медперсонал, медучреждение и т. д., корень -мед- является псевдоэтимологическим по причине его несовместимости с префиксом архи-, сочетающимся только с прилагательными и обозначающим максимальную степень проявления того или иного признака (архисложный, архиважный, ...).

В данном случае этот префикс выполняет исключительно функцию внутренней рекламы, т.е. функцию привлечения внимания потенциального потребителя позитивной коннотацией одного из словообразовательных элементов, использованных при создании игрового деривата. Подробнее о понятии внутренней рекламы см. [6].

В особую группу игровых производных с префиксальными формантами можно выделить игровые названия лекарств с приставками со значением отрицания основы. «Все они имеют прозрачную внутреннюю форму. Основа называет болезнь, недомогание или содержит намёк на его неприятные последствия...: aнmuxpan, aнтиполицай,... негрустин» [3, с. 189-190]. 
При образовании таких игровых названий лекарств также можно говорить о наличии внутренней рекламы за счёт использования приставок со значением отрицания. В данном случае эффект внутренней рекламы обусловлен не привлечением внимания потенциального потребителя позитивной коннотацией одного из словообразовательных элементов, использованных при создании игрового деривата, а, наоборот, уверением потенциального потребителя в том, что, используя данный товар, он обезопасит себя от проблем, констатируемых корнем слова.

Итак, в неузуальном игровом словообразовании префиксальный способ значительно менее популярен, чем в узуальном. Игровой дериват АрхиМед создан не по канонической модели префикс + корень (ср. делать-сделать), а с использованием псевдоэтимологизации и графиксации. То есть игровой дериват образован с опорой на звуковой облик слов-стимулов и с использованием графических средств выделения значимых частей словообразовательной структуры деривата.

Более канонически образованы игровые названия лекарств антuxpan, антиполицай, негрустин. Однако в игровом деривате негрустин помимо префиксации прослеживается тенденция к блендингу [6], так как конечный элемент -ин позволяет предположить наличие у этого игрового деривата слова-стимула типа клофелин, анальгин и т.д.

\section{Суффиксашия}

В неузуальном игровом словообразовании суффиксация является наиболее продуктивным аффиксальным способом словообразования.

\section{Группа суффиксов, создающая эффект умиления}

\section{Суффикс -онок/-ёнок}

Название интернет-магазина игрушек Пчелёнок произошло от имени героя одного из популярных детских мультфильмов. Комизм этого названия возникает из-за прибавления к корню слова пчела, называющего вид насекомого, суффикса -ёнок, характеризующего детёнышей животных. «Интернет-магазин детских игрушек Пчелёнок не осуществляет гарантийное и послегарантийное обслуживание проданных товаров» (http://www. pchelenok.com/)* .

Аналогичным способом образован дериват Мебелёнок, являющийся названием компании по производству мебели для детей. В данном случае корень слова называет неодушевлённый предмет, что, по сравнению с пчелёнком, ещё более усиливает комизм, поскольку суффикс -ёнок характеризует детёнышей животных. «На фрабрике «Мебелёнок» производится детская мебель из массива бука, дуба и Ангарской сосны» (https://www.kidsreview.ru/).

Наиболее интересным со словообразовательной точки зрения представляется дериват Спелёнок, называющий торговую марку детского питания. «Спелёнок - это отличный выбор современных родителей, которые хотят покупать для своих детей только самые качественные, вкусные и безопасные продукты nо принципу наилучшего сочетания чена-качество» (https://spelenok.com/). Данный дериват образован не обыкновенным прибавлением суффикса к корню, а слиянием словосочетания и формированием псевдоэтимологического суффикса -ёнок из части корня и суффикса: предлог с в словосочетании «с пелёнок» превращается в приставку, а из части корня -ён- и суффикса -ок слова пелёнок формируется псевдоэтимологический суффикс -ёнок, характеризующий, как уже было сказано, детёнышей животных.

\section{Суффикс -инк}

Данный суффикс присутствует в деривате чудесинка, называющем торговую марку трубочек для молока с различными вкусами. Игровая составляющая в данном случае обусловлена невозможностью выделить один элемент из множества ему подобных (ср. чаинка, бусинка, горошинка,...) по причине отсутствия материального денотата у слова чудо. «Хотелось рассказать о коктейльных трубочках «Чудесинка со вкусом банана» (https://otzovik.com).

Интересно, что сам производитель предлагает другую этимологию своего онима: «Чудесинка Расти Большой - это чУДЕСная соломИНКА, содержащая сахарные гранулы, которые придают молоку твой любимый вкус: клубника, банан, шоколад, лесные ягоды, карамель!» (https://vk.com/chudesinka_rb). Однако эта этимология представляется упрощённой, т.к. никакой фонетической отсылки к корню слова-стимула соломинка в деривате нет (ср. стиратели (ластики в виде героев мультфильмов): старатели + стирать).

Суффикс -ик встречается в игровом деривате Cnopтик, называющем торговую марку детской питьевой воды. Здесь, как и выше, комизм обусловлен несочетаемостью абстрактного существительного спорт и уменьшительно-ласкательного суффикса -ик, прибавляемого к корням, имеющим вещественный денотат (ср. домик, листик,...). «Удобный размер бутылочки позволяет всегда брать Спортик с собой, ведь он поместится в любой рюкзак или сумку» (https://sportik.svyatoyistochnik.com/).

Суффикс -к содержат коммерческие игровые дериваты Annemuтка и Амка. Дериват Аnпетитка называет 
торговую марку соусов и закусок, а дериват Амка - торговую марку кисломолочной продукции для детей. («Закуска «Аппетитка» на основе помидоров и стручкового периа» (https://www.wildberries.ru/). «Хочу поделиться свочми впечатлениями о молочной продукции "Амка»» (https://otzovik.com/). И опять абстрактное, не имеющее вещественного денотата слово, заключённое в корне (в первом случае - существительное annemum, во втором междометие $а м)$, соприкасается с суффиксом, имеющим предметное стилистическое значение (ср. табуретка, книжка, дужка).

Ещё один пример игрового деривата, образованного прибавлением суффикса -к - слово аддурилка. «Под понятием «аддурилка» подразумевается особая страница, имеющаяся у каждой поисковой системы и на которой расположена специальная форма для сообщения поисковику о том, что появился новый сайт или новая страница» (http://www.raskruty.ru/). «Cтоит заметumь что практически у всех популярных поисковых систем есть свои аддурилки, например: аддурилка яндекса или аддурилка Google» (http://cms-all.ru/). Игровой дериват получился путём транслитерации английского словосочетания «add url» с последующим прибавлением с суффикса -к, придающего разговорное значение (ср.: Вася Васька, дядя $\rightarrow$ дядька). На русификацию англоязычного словосочетания могло повлиять так же и разговорное название рыболовной снасти дурилка.

Суффикс-к содержало исходное название сети ресторанов японской кухни: Япошка. Однако в данном случае в игровое словообразование вмешалась политика, и «из соображений политкорректности владельцы заведения изменили название самого кафе: в результате «отказа» от уменьшительного суффикса -к- родился неологизм япоша (япошка - япоша), который, как и окказионализм цветоша, вызывает ассоциативную связь с ласкательными формами личных имен. Со словообразовательной точки зрения такое производное существительное является результатом редеривации, связанной с отсечением форманта» $[10$, с. 5$]$.

Группа суффиксов, создающая существительные с абстрактным значением

Суффикс -изм встречаем в деривате котизм. Попытка толкования данного деривата представляет собой некоторые трудности, ибо так называют и просто фото котов, и видео с юмористическими подборками про котов, и форумы, посвящённые содержанию котов, и т.д. Пожалуй, наиболее всеобъемлющим является данное объяснение: «Котизм - это такая неизлечимая болезнь, когда хочется потискать всех котиков и кошечек, встречающихся на пути!» (https://otvet.mail.ru/). Здесь суффикс -изм, маркирующий различные течения/ воззрения (ср. ленинизм, капитализм, романтизм, сто- ицизм), соседствует с названием рода животных кот. Дериват кобелизм представляется семантически более прозрачным, однако так же нуждается в толковании: «Он от жены давно привык «ходить налево», Его распутный кобелизм неизлечим!» (https://www.inpearls.ru/)

Суффикс -ств содержится в игровом деривате кнопкодавство, характеризующем распространённую в Верховной Раде Украины практику голосования одних депутатов за других. В данном случае суффикс, предполагающий наличие перед собой корня, в семантике которого заложено отвлечённое понятие (ср. ханжество, уродство, богатство), соседствует с корнем, представленным игровым дериватом кнопкодав, имеющим вполне конкретное толкование. «Инновации на -ство с собирательным значением могут иметь шутливый характер, ср.: Крабство и кокосство (название статьи о Мальдивских островах). В роли мотивирующей базы в данном случае использованы неодушевленные существительные, что и вызывает ощущение необычности нового слова» $[4$, с. 22$]$.

Суффикс - $\boldsymbol{u}[\mathbf{j}]$ присутствует в деривате вырвиглазие, называющем тот или иной с трудом визуально воспринимаемый объект. Проблемы восприятия в таком случае вызваны плохой контрастностью и китчевым сочетанием цветов, а иногда - недостаточно крупным шрифтом. «Без скриншота не совсем понятно, что имеется в виду под вырвиглазием» (https://forum.ubuntu.ru/). Дериват встречается так же как характеристика тяжёлых для зрения мелких манипуляций: «Потому и паяться к резьбовому соединению тиристора, диода, транзистора и т.д. и m.n. без цивилизованного использования лепестка - ересь и вырвиглазие» (http://yagotin.info).

Встречается суффикс $-u[j]$ и в форумной лексике в качестве форманта, создающего игровые отглагольные существительные: «водили кота на дефабержирование $\leftarrow$ дерабержировать 'кастрировать'; С окунячиванием вас! $\leftarrow$ окунячиваться 'заводить кота породы мейнкун'; можно подумать, что те, кто производит щенков с документами, «не справляются» с особачиванием всех желающих?! » [9, с. 561].

Суффикс-ость/-ность породил группу игровых дериватов, таких, как чернушность («Многие его не любят за чернушность сюжетов, но мне эта тема очень близка» (https://irecommend.ru/), КВНистость («Тема, в принuиnе, благодарная, только сухости убавить, а добавить КВНистости, что ли» (https://web-silver.ru/), змеиность («Змеи с ногами заставили зоологов пересмотреть представления о «змеиности» (http://sci-dig.ru/), мармеладность («Затянувшаяся мармеладность в отношениях - признак неискренности» (https://otvet.mail.ru/). Представляет интерес развитие словообразовательной цепочки от слова мармелад в области игровой дерива- 
ции, а именно, возникновение глагола мармеладничать.

Суффикс -иад обнаружен в составе игрового деривата выбориада. «Выбориада 2015: Как укоротить трехметровый бюллетень?» (https://oren.mk.ru/). Комизм данного существительного обусловлен тем, что «согласно точке зрения РГ-80, существительные на -ада могут мотивироваться только названиями лиц: арлекинада, клоунада и др». [4, с. 24]

Группа суффиксов, создающая эффект имени собственного

\section{Суффикс-ыч/-uч}

Встречаясь в дериватах Пакетыч (торговая марка мешков для мусора, «Мешки для мусора «Пакетыч» 30л» (https://moskva.kassot.com/) и «Дым Дымыч» (торговая марка колбасных изделий, «Мясные продукты под брендом Дым Дымыч покупаю уже давно» (https://irecommend. ru/), суффикс -ыч/-ич создаёт эффект антропоморфности неодушевлённого образа, запечатлённого в семантике корня, за счёт копирования морфемного состава отчества человека. Во втором случае это копирование поддержано наличием игрового имени собственного дым и эмблемой фирмы.

Суффикс -ович встречается в названии продуктового магазина Продуктович. «Магазин Продуктович занимается: кормами для кошек, розничной продажей продуктов, черным чаем, батарейками, спаржей, сельдереем, белыми грибами, зелеными помидорами, красной смородиной, апельсиновым соком, черникой, голубикой, печеночным паштетом, соленой рыбой» (https://asktel.ru/).

\section{Суффикс-офф/-ов}

«Тот же принцип квазионимизации лежит в основе номинации ресторанов «Мяснофф», «Блинофф», «Колбасофф», «Пельменефф», в которых, кроме того, используется такой лингвокреативный элемент, как иноязычный суффикс -off, но переданный кириллицей («обратная транслитерация»)» $[10$, с. 136]

По такому же принципу, но с добавлением стилизации под дореволюционную эпоху, образованы названия компаний Мясоедовъ и Мясновъ. Стилизация в данном случае возникает за счёт добавления буквы Љ, отменённой в 1918 году декретом Совета народных комиссаров.

Суффикс -ин встречается в названиях рубрик в одном из каталогов продукции компании Avon: Дискотекино и Освежайкино. В данном случае комизм базируется на создании псевдотопонима (ср. названия районов Москвы Марьино, (Южное) Бунино, городов Пущино,
Колпино). Следует заметить, что иногда и реальные названия населённых пунктов могут напоминать игровой дериват, как, например, село Улиткино, расположенное в Ногинском районе Московской области.

\section{Суффикс-очн/-ечн}

В узуальном словообразовании данный суффикс участвует в формировании названий типов учреждений, образованных от названий товаров или профессий (булочная, прачечная,...). Включение этого суффикса в группу суффиксов, создающих игровые дериваты, оправдано наличием слова Козявочная, называющего магазин товаров для рыбалки в Екатеринбурге, расположенного «nо адресу Россия, Свердловская область, Екатеринбург, улица Белинского, 248» (https://yandex.ru/maps/). Комизм данного игрового деривата базируется на том, что козявка - жаргонное название любого мелкого насекомого.

Группа суффиксов, создающая эффект процессуальности

\section{Суффикс-изаци[j]}

Из целой группы дериватов с таким суффиксом (nутинизация, обамизация, ...) выделим один наиболее яркий дериват: медведизация. C конца XX века по наше время он представлен тремя значениями:

Значение 1. Конец 90-х гг. XX в. Распространение по России медведя - символа партии «Единство»: «Как бы то ни было, после успехов «Единства» на выборах 1999 года медведь продолжил свое шествие по политическим тропам - причем настолько успешное, что впору говорить о «медведизачии» России» (https://magazines.gorky.media/).

Значение 2. Годы президентства Д.А. Медведева. Модернизации, проведённые Д.А. Медведевым и не поддержанные общественностью. «Суть медведизации создание иллюзии желанного могущества и порядка, поддержка надежды на прогресс» (https://maxpark.com/).

Значение 3. 2018-2019 гг. Характеристика успеха и последующего за ним увеличения популярности фигуристки Евгении Медведевой. «Евгения Медведева и медведизация всей страны, или «люби меня, люби» (https://cont.ws/).

Наиболее популярным значением из представленных является второе. Комизм в этом случае выражен несочетаемостью суффикса -изаци[j] и фамилии человека.

\section{Суффикс -инг}

Волна «улучшайзинга под контроллингом» [1:121] 
привела к появлению в игровом словообразовании русского языка новой тенденции - использованию заимствованного английского суффикса -ing для обозначения давно поименованных понятий. С помощью этого суффикса образовалась целая группа слов, таких, как дышатинг, гулятинг, смотретинг. Следует заметить, что этот суффикс в игровом словообразовании активно прибавляется не только к глаголам, но и к существительным (шашлыкинг), и даже к наречиям (пешкаринг). «Регламент пока не обозначен, но хотелось бы шашлыкинга и свежем воздухом дышатинга, если будет желание» (https://www.pickupclub.ru/) «Подъём 7 - 7:30, ежедневныле радиальные выезды/выходы из пвд исходя из текущей дорожно-погодной обстановки, лошадинг, походный банинг для экстремалов, пешкаринг (если вдруг джипинг удастся на славу), экскурсинг (для тех кто не был) и свежим воздухом дышатинг, мафиозинг и крокодилинг nо вечерам в пвд» (https://www.sites.google.com/). «Как всегда, смешон не сам суффикс, не его заимствование, смешна мода на него» [1, с. 122], возникшая в молодёжном сленге и даже вышедшая на уровень официальной деловой лексики: «Вебинар «Смотретинг: видеомаркетинг в новой парадигме»» (https://zillion.timepad.ru/).

Группа суффиксов, создающая эффект названия местности или жителя местности

\section{Суффикс-чанин}

С его помощью образовались такие игровые дериваты, как клубчанин и форумчанин, создающие эффект жителя клуба или форума. Комизм данных игровых дериватов обусловлен тем, что суффикс-чанин используется только с корнями, во-первых, реальных, и, во-вторых, русских городов и сёл (ср. анапчанин, норильчанин, ...).

\section{Суффикс-щин}

Теме игрового словообразования в области географии можно посвятить отдельное исследование, рассматривая часто встречающиеся игровые дериваты, созданные по схеме «название зарубежного города + русский суффикс». «Был на парижщине на НГо8. Не сказать, что разочарован, но абсолютно не витырило» (https:// tourout.ru/), «Лондоншина в иене... Россияне предпочитают жилье в центральных районах Лондона - Челси, Вестминстер, Кенсингтон, Мейфейр» . (https://aleks1958. livejournal.com/)

Группа суффиксов, создающая эффект производителя действия

\section{Суффикс -ер}

С его помощью образовано название типа игрушек Прыг-скокер, представляющих из себя прыгающие разноцветные мячики, внешне напоминающие воланчики для бадминтона. Суффикс -ер вошёл в русский язык для обозначения профессии или статуса (ср. брокер, пенсионер, флибустьер), однако для называния типа игрушек в узуальном словообразовании не используется.

\section{Префиксально-суффиксальный способ}

Этот аффиксальный способ словообразования в игровой деривации используется реже, чем суффиксалый. Ниже представлены три модели образования префиксально-суффиксальных игровых существительных, различающиеся только префиксальной частью и имеющие общий суффикс [j].

Префикс под- + суффикс [j] представляет собой популярную модель образования игровых дериватов, создающих эффект названия местности. «Фоторассказ о наших прогулках в Подмиланье» (http://travels-journal. ru/), «Кусочек Рублевки в Подлондонье» (https://www. tripadvisor.ru/).

Префикс без- + суффикс [j] обнаруживаются в составе таких игровых дериватов как безмерседесье и безкартинье. «На безмерседесье и «Жигули»- автомобиль!» (https://forum.ixbt.com/). «Эпоха безкартинья» - заголовок статьи на сайте https://www.vsyzrani.ru/ в память о художнице Эльвире Беделяевой.

Префикс за- + суффикс [j] обнаруживаются в составе таких игровых дериватов как забугорье, замкадье и задверье. «Итак, раз уж мы решили всей бригадой ломануться в забугорье, осталось решить - куда именно!» (https://forum.garant.ru/) «Замкадье - самый большой по площади регион страны, расположенный вокруг Москвы и отгороженный от неё МКАДом по всему перимеmру» (https://eriklobakh.livejournal.com/). «Никогде» (англ. Neverwhere), в другом переводе «Задверье» — роман Нила Геймана в жанре городское фэнтези. Это новелизация его собственного сиенария для одноимённого сериала» (https://ru.wikipedia.org/).

\section{Выво $\Delta ы$}

І. Из всех способов аффиксального словообразования, используемых в рамках узуального словообразования, в игровом словообразовании существительных активно используются три способа:

1. префиксация (АрхиМед, антиполицай, антихрап, негрустин),

2. суффиксация (клубчанин, кнопкодавство, медведизация, амка,...),

3. префиксально-суффиксальный способ (Подмиланье, Подлондонье, безмерседесье,...).

Из 59 игровых дериватов-существительных, разобранных в данной статье, префиксальных - 4 (7\%), суффиксальных - 48 (81\%), префиксально-суффиксальных - 7 (12\%) 
II. Наиболее продуктивны суффиксы, так как на основе несочетаемости их семантики с семантикой корня создаётся комический эффект, необходимый при игровом словообразовании. Префиксы в игровом словообразовании менее популярны, так как их семантика шире, чем семантика суффиксов, и поэтому труднее поддаётся комическому переосмыслению.

III. Игровые аффиксаты-существительные распространены в интернете, СМИ и рекламе, а так же в названиях торговых марок.

${ }^{*} B$ этой и последующих цитатах из интернета сохранена орфография автора.

\section{ЛИТЕРАТУРА}

1. Кронгауз М.А. Русский язык на грани нервного срыва. 3D. М.: Астрель, 2012.480 с.

2. Санников В.3. Русский язык в зеркале языковой игры. 2-е изд. М.: Языки славянской культуры, 2002. 552 с

3. Земская Е.А. Игровое словообразование// Язык в движении: К 70-летию Л.П. Крысина. М., 2007. С. 186-193.

4. Ильясова С.В. Словообразовательная игра как феномен языка современных СМИ //Автореф. Дисс. На соискание уч. Степ. Доктора филологич. Наук / Ростов-на-Дону, 2002 г. 55 С.

5. Дедова 0.В, Григорьева П.В. Игровое словообразование в современном русском языке. Вестник Московского университета. Серия 9: Филология. 2018; № $5: 49-64$

6. Григорьева П.В. Блендинг как тип неузуального словообразования: к уточнению понятия//Мир науки, культуры, образования №3 (76) 2019. С. $488-490$

7. Земская Е.А. Словообразование // Современный русский язык/Под ред. В.А. Белошапковой. М.: Высшая школа, 1989.

8. Попова Т.В. Русская неология и неография. Екатеринбург: 2005. 96 с.

9. Щеникова, Е.В. Неузуальные отглагольные существительные с абстрактной семантикой в форумном дискурсе // Динамика языковых и культурных процессов в современной России. 2018. № 6. С. 560-565.

10. Ремчукова Е.Н, Махиянова Л.Р. Лексико-грамматические механизмы лингвокреативности в сфере городской номинации//Вестник РудН, серия Теория языка. Семиотика. Семантика, 2015, № 2

(с) Григорьева Полина Вениаминовна (paulines@yandex.ru).

Журнал «Современная наука: актуальные проблемы теории и практики»

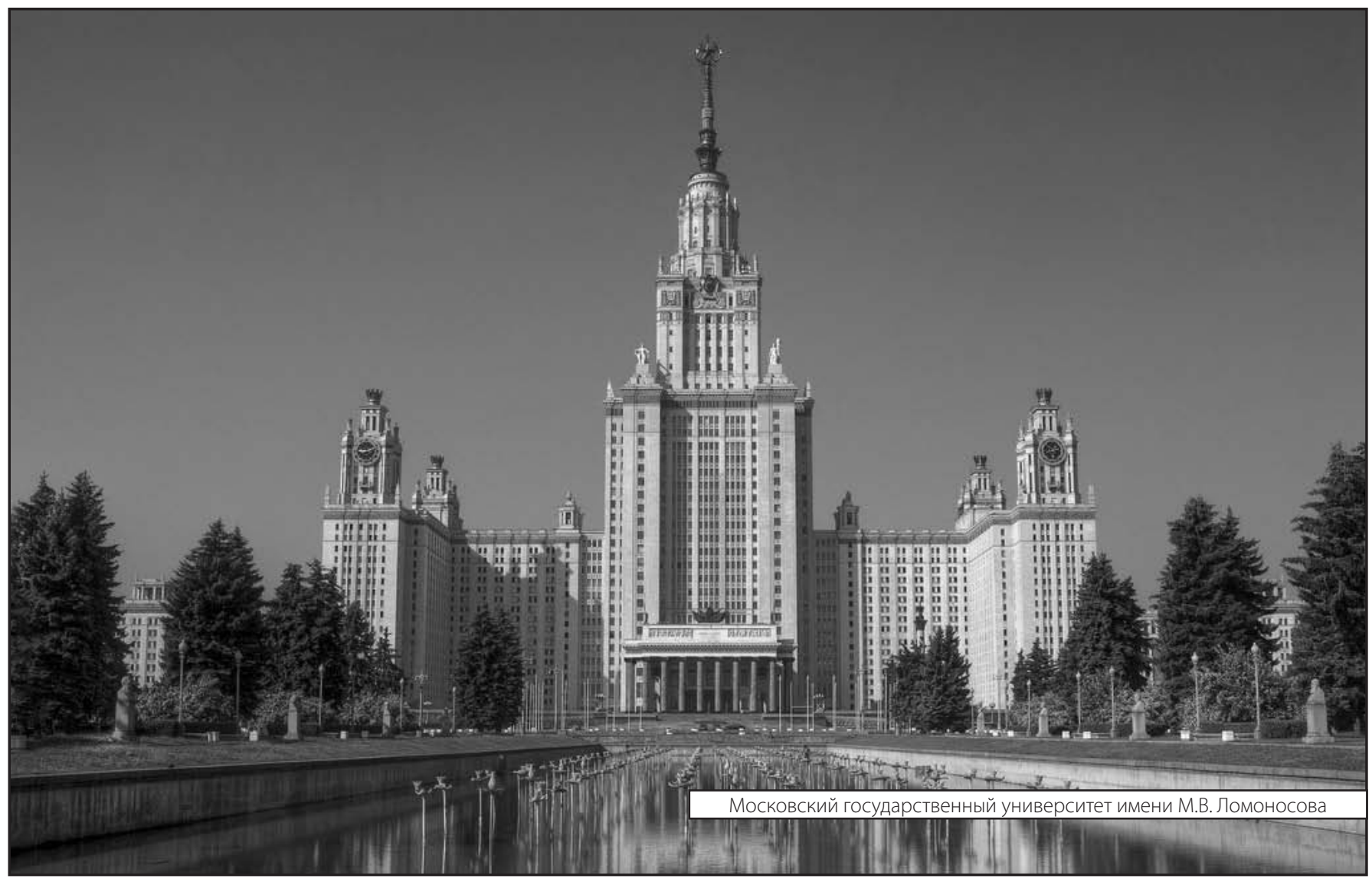

